\title{
Verzeichnis der Abbildungen
}

Abbildung 1: Die einzelnen Elemente in den verschiedenen Vergleichsstrukturen ..........................

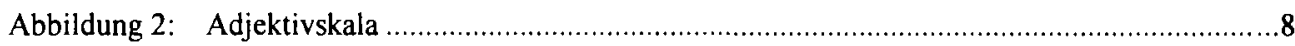

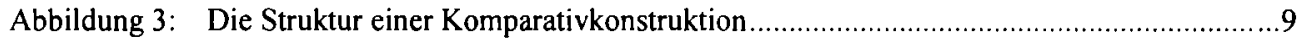

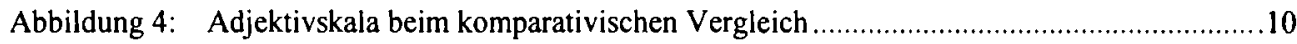

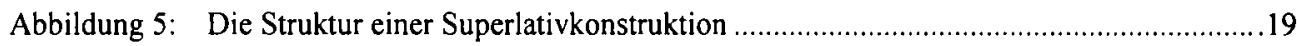

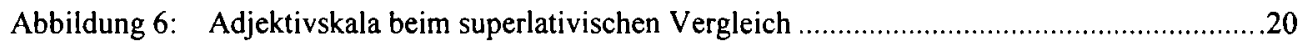

Abbildung 7: Die Struktur eines Vergleichs mit so [ADJEKTIV] ..................................................28

Abbildung 8: Die Struktur eines Vergleichs mit so + Verbalphrase ..............................................35

Abbildung 9: Die Struktur einer Komparativkonstruktion ........................................................47

Abbildung 10: Struktur von Komparativkonstruktionen mit einem wenn-Satz ...............................60

Abbildung 11: Die Struktur eines Äquativvergleichs...................................................................74

Abbildung 12: Die Struktur eines Modalitătsvergleichs mit so - wie + Verb-Letzt-Satz .................76

Abbildung 13: Die Struktur eines Modalitätsvergleichs ohne so ....................................................78

Abbildung 14: Systemverschiebung der Vergleichsjunktoren .......................................................96

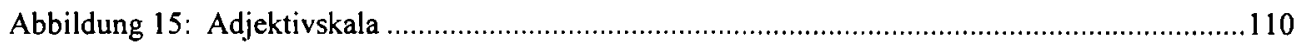

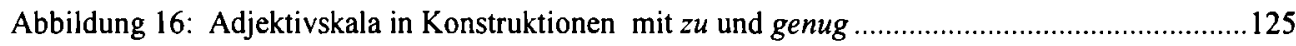

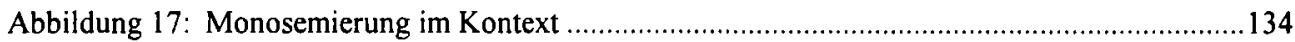

Abbildung 18: Ausprägungsgrade verschiedener Entitäten auf der Skala von

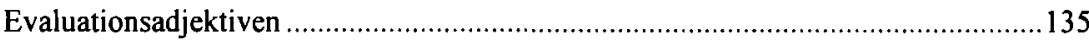

Abbildung 19: Ausprägungsgrade verschiedener Entitäten auf der Skala von

Dimensionsadjektiven ................................................................................ 135

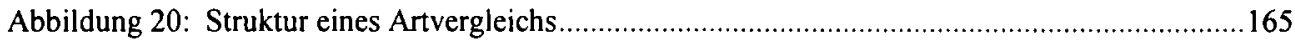

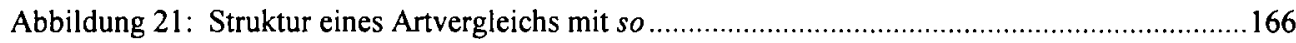

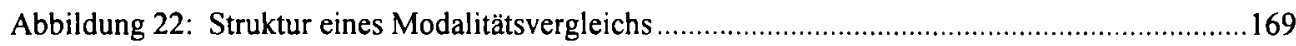

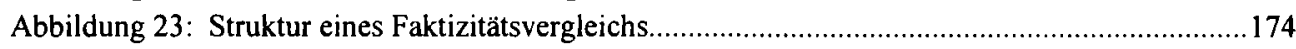

Abbildung 24: Vergleichsstrukturen mit attributivem Komparativ ............................................... 185

Abbildung 25: Topologische Charakteristika von Komparativkonstruktionen ..............................195

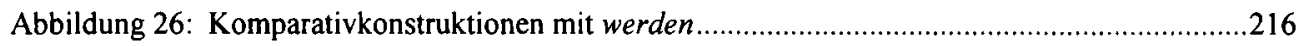

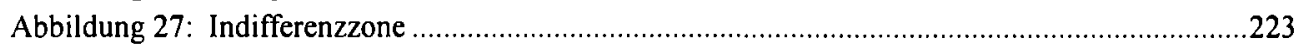

Abbildung 28: Attributiver Superlativ: einfacher Vergleichsaspekt, komplexe Vergl.entitäten ........244

Abbildung 29: Attributiver Superlativ: komplexer Vergleichsaspekt, einfache Vergl.entitäten ........244

Abbildung 30: Topologische Charakteristika skalarer Gradvergleiche ..........................................260

Abbildung 31: Topologische Charakteristika von Artvergleichen ..........................................272

Abbildung 32: Formen von Komparandum und Komparationsbasis bei Artvergleichen ..................275

Abbildung 33: Topologische Charakteristika valenzgeforderter und valenzfreier Modalitătsvergleiche in der Abfolge Komparandum vor Komparationsbasis............................224

Abbildung 34: Topologische Charakteristika valenzgeforderter und valenzfreier Modalitätsvergleiche in der Abfolge Komparationsbasis vor Komparandum .........................295

Abbildung 35: Topologische Charakteristika satzförmiger Komparationsbasen in Modalitäts-

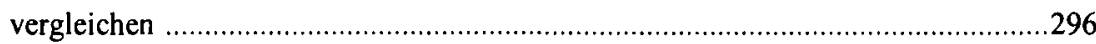

Abbildung 36: Topologische Charakteristika von Faktizitätsvergleichen ........................................300 
